\title{
The CORE-CARE laboratory to investigate the indoor environmental quality in buildings
}

\author{
Marco Marigo ${ }^{1}$, Giulia Alessio ${ }^{1}$, Sara Bordognon $^{1}$, Enrico Prataviera ${ }^{1}$, Laura Carnieletto ${ }^{1}$ \\ , Beatrice Biasia ${ }^{1}$, Antonino Di Bella ${ }^{1}$, Michele De Carli ${ }^{1, *}$, and Angelo Zarrella ${ }^{1}$ \\ ${ }^{1}$ Department of Industrial Engineering, University of Padova, 35131 via Venezia 1, Padova, Italy
}

\begin{abstract}
In this work, the climatic chamber CORE-CARE is presented. The laboratory was built at the Industrial Engineering Department of the University of Padova, in order to further investigate issues related to indoor environmental quality, the comfort perceived by people in confined spaces and thermal performance of radiant systems. CORE-CARE is equipped with radiant panels in each surface, which can be controlled separately. The room presents two real windows on the East side, equipped with shading systems. Furthermore, the mechanic controlled ventilation system installed in the room can act as integration of sensible or latent heat both in heating and in cooling conditions. The climatic chamber is provided with a data acquisition system, consisting of 38 sensors, that allow the evaluation of the surface temperatures in different positions, the air temperature at different heights, the mean radiant temperature, relative humidity and $\mathrm{CO}_{2}$ concentration. The CORE-CARE chamber is thermally characterized using a detailed model developed at the Industrial Engineering Department of the University of Padova and the simulations results are compared with test measurements. Moreover, the impact of radiant asymmetry is investigated.
\end{abstract}

\section{Introduction}

Nowadays, the perceived comfort inside buildings is one of the most relevant issues investigated in the literature. Indeed, people spend most of their time in indoor spaces and, for this reason, topics concerning the indoor environmental and air quality are widely discussed. The COVID-19 pandemic has further emphasized these aspects, especially the ones related to ventilation as a measure to prevent the airborne transmission of diseases. In this context, the use of climatic chambers for the investigation of comfort inside buildings is an established practice and it has been widely used in past works.

The definition of comfort was firstly given by Fanger as a result of his studies, carried out during the 60s and subsequently published [1]; he reached the definition of the comfort equation, based on the heat balance of a body interacting with the surrounding environment. In particular, some tests carried out in a climatic chamber were used for the evaluation of the comfort limits due to the radiant asymmetry: by means of measurements and surveys of tested subjects, he set limits for acceptable comfort condition with regard to radiant asymmetry in case of warm ceiling [2], cool ceiling, warm wall and cool wall [3]. On this

\footnotetext{
* Corresponding author: michele.decarli@unipd.it
} 
topic, more recent studies substantially confirmed the results obtained by Fanger; among them Zhou et al. [4] extended the approach proposed by Fanger to a cool floor, considering two temperature limits for different exposure time of $2 \mathrm{~h}$ or $8 \mathrm{~h}$ in the considered room. This study was carried out with a similar methodology to the one proposed by Fanger, based on both measurements and survey.

Following the publication of the comfort equation, some authors tried to test in climatic chambers which causes of discomfort could affect more the thermal sensation of tested subjects, who gave their feedback through surveys. Moreover, the surface skin temperature of the subjects was monitored, to verify the influence of external factors and the consequent perceived thermal sensation. Olesen et al. [5] tried to evaluate the physiological comfort conditions, according to variations of different parameters; they found that at a given activity level, the skin temperature was independent from any combination of clothing, mean radiant temperature, air temperature and air velocity. A more recent study [6] tried to evaluate the effect of age on thermal comfort perception, with results indicating that thermal sensation of the elderly was, in general, 0.5 scale units (on a 7-point thermal sensation scale) lower in comparison with their younger counterparts.

Another important issue related to tests carried out in climatic chambers is the comparison of different systems for the analysis of indoor thermal comfort. In this regard, a recent study by Cen et al. [7] compared the behaviour of thermal comfort in cooling conditions with a fan coil system and radiant floor system at varying space heights in a chamber with movable ceiling; they found significant differences in terms of thermal comfort and operative temperature for the fan coil system and the radiant floor system; moreover, they stated that fan coil systems are more suitable for low space height environments, while radiant floor systems provide better thermal comfort in high height environments. Sun et al. [8] compared the use of three different terminals (floor-mounted and wall-mounted air conditioner, radiant floor) during heating season, both in steady and transient conditions; they found that in steady conditions, there was no significant thermal comfort difference between the tested systems; on the contrary, during transient operations, a higher stratification and air velocity was found in air conditioning solutions.

Finally, in some works the climatic chamber is used to validate numerical models: Catalina et al. [9] carried out a calibration of a CFD model through experimental data coming from a test room to evaluate air velocity in case of cooled ceiling. Dong et al. [10] found a significant effect of the solar radiation on thermal comfort using numerical analysis and measurements on a climatic chamber.

In this work, the CORE-CARE laboratory is presented. It is a climatic chamber built at the Department of Industrial Engineering of the University of Padova. The aim of the laboratory is to give a contribution to issues concerning the indoor thermal comfort through experimental estimations based both on measurements of quantities related to thermal comfort and on surveys of subjects exposed to different environmental conditions. The objective of this work is to reach a knowledge of the dynamic behaviour of the room: in order to manage the boundary conditions for future tests, the characterization the of the test room is necessary to understand the correlation among different quantities (e.g. correlation between supply temperature and wall surface temperatures, time to reach steady conditions for each configuration, dependence of the air temperature from surfaces temperatures); to reach this goal, the test room was modelled using the software DigiThon [11] and the obtained results were compared to measurements collected in the room. 


\section{Description of the climatic chamber}

The CORE-CARE laboratory (controlled room for building environmental comfort assessment and subjective human response evaluation) is a climatic chamber of the Department of Industrial Engineering of the University of Padova. The laboratory was set up with the aim of investigating and measuring thermal comfort parameters in order to face the growing interest in recent years in Indoor Environmental Quality (IEQ).

\subsection{Geometrical and constructive characteristics}

The laboratory consists of the test room and the control room (Figure 1). The climatic chamber has an area of $17.66 \mathrm{~m}^{2}$ and a height of $2.79 \mathrm{~m}$; the east wall is the only one bordering on the outside and has two windows; there are no buildings outside that could shade the external facade. The west wall is adjacent to a corridor, the north wall and the floor border with two conditioned rooms, the south wall is adjacent to the control room, and the ceiling is separated from the outside of the building by an air gap.

In the test room radiant wall, ceiling and floor systems have been installed, as well as a controlled mechanical ventilation system and sensors to measure environmental parameters. In the control room the primary circuits for heating and cooling, the tanks required for the hot, cold and chiller circuit and the ventilation machine are placed.

Two double glazed windows with glass $6 \mathrm{~mm}$ thick and a $16 \mathrm{~mm}$ argon-filled gap and the PVC frame are installed in the test room.

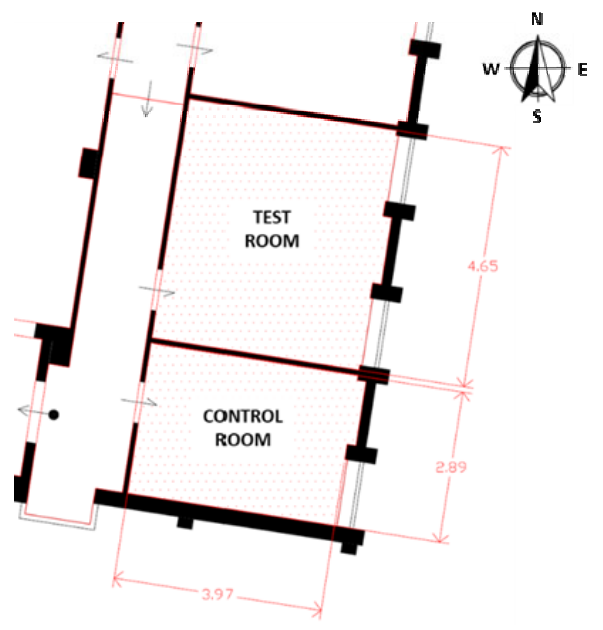

Fig. 1. Plan view of the CORE-CARE laboratory.

\subsection{Description of radiant systems}

The laboratory is equipped with radiant panels in each surface (walls, floor and ceiling) which can be supplied with hot or cold water (Figure 2). The floor has a radiant system embedded in a quartzite resin screed. Radiant panels of different materials and configurations are used in the other walls and ceiling. 


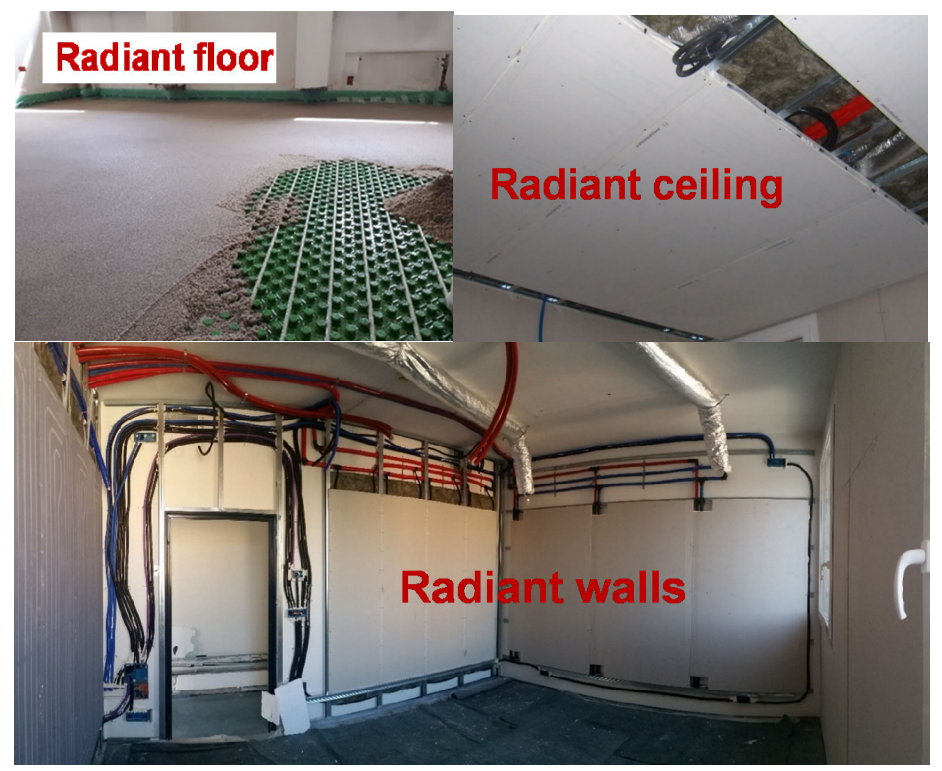

Fig. 2. Radiant systems installed in CORE-CARE laboratory.

The radiant systems of the six surfaces are supplied with water from six secondary circuits, each of which has its own dedicated mixing and pumping unit. The secondary circuits flow into modular manifolds, which are connected both to the heating and cooling primary circuit. In the control room there are three tanks for the fluids used by the radiant system circuits and for the mechanical ventilation system. The heating circuit has a $200 \mathrm{~L}$ tank. The water is heated by three electrical resistances. The cooling circuit has a $100 \mathrm{~L}$ tank; it is decoupled from the chiller circuit by means of a plate heat exchanger. The chiller circuit is treated with a $30 \%$ dosage of antifreeze to prevent corrosion and ice formation down to $-15^{\circ} \mathrm{C}$. The circuits installed in the control room are shown in Figure 3 .
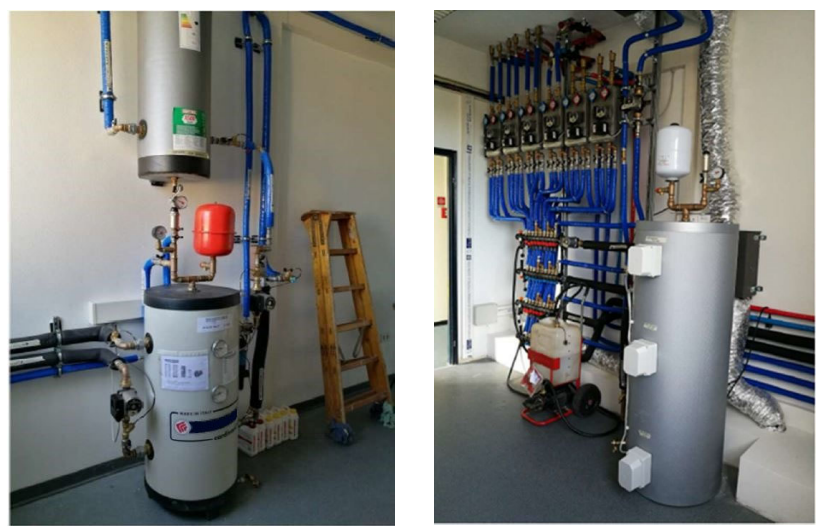

Fig. 3. Cooling tank and connection with chiller circuit (left); heating tank and secondary circuits (right). 


\subsection{Ventilation system}

The mechanical ventilation system consists of a primary air unit for the renewal of ambient air and the control of relative humidity with high efficiency heat recovery, shown in Figure 4. There is the possibility of integration in heating and cooling mode, which is carried out thanks to the hydraulic connection to the heating and refrigeration circuit. This is a full external air system with by-pass for free cooling.

The two inlet nozzles are located on the ceiling (height of $2.79 \mathrm{~m}$ ), in the area adjacent to the North wall, $12 \mathrm{~cm}$ away from it, and are positioned symmetrically $64.5 \mathrm{~cm}$ from the East and West walls. The exhaust air inlets are located in the lower part of the South wall, symmetrically placed $80 \mathrm{~cm}$ far from the East and West walls, both at a height of $9 \mathrm{~cm}$ from the floor.

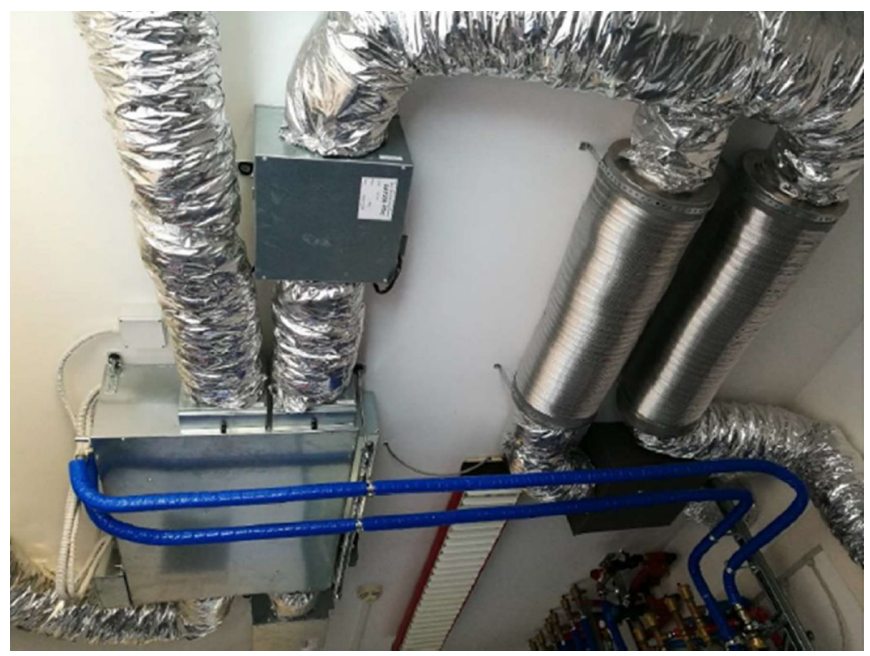

Fig. 4. Picture of the ventilation unit and connections with heating and cooling circuits (blue pipes).

\subsection{Acquisition system}

The internal data acquisition system of the test room consists of 32 sensors. Inside the climatic chamber there are:

- 26 sensors for the measurement of the surface temperature of the six surfaces of the climate chamber;

- 3 sensors for measuring the air temperature, located on the vertical column positioned in the centre of the room at three different heights $(0.1 \mathrm{~m}, 0.60 \mathrm{~m}$ and $1.70 \mathrm{~m})$;

- 1 sensor located on the vertical column at a height of $1.1 \mathrm{~m}$ to measure temperature and relative humidity;

- 1 globe thermometer for the measurement of mean radiant temperature, placed on the column;

- 1 sensor to assess the $\mathrm{CO} 2$ level inside the room.

In each wall there are four surface temperature sensors which are placed at different points of the surface. In addition, in each of the two windows the surface temperature is measured by one of these sensors. In Figure 5, part of these sensors is shown. 


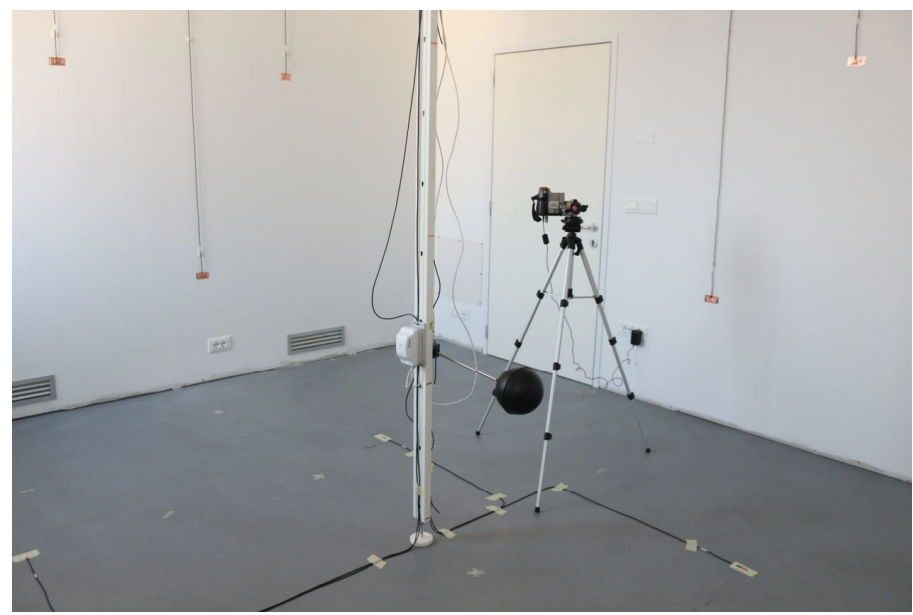

Fig. 5. Acquisition system installed in CORE-CARE.

\section{DigiThon model}

The CORE-CARE laboratory was modelled with the software DigiThon, developed at the University of Padova. This model is based on the transfer function method [12] and it simulates all types of radiant system, since respective transfer functions can be precalculated via a detailed two-dimensional model based on the finite-difference or finiteelement methods. It also considers the full thermal balance [13] for the room, taking into account internal loads, solar radiation, ventilation and infiltration. In DigiThon, each room surface can contain sub-surfaces (named regions), e.g. a window or a part of the wall made of different materials. Each sub-surface is discretized by means of elements, named tiles, corresponding to inner and external surface thermal nodes. The air thermal node is considered for the room's entire air volume, which is assumed to be completely mixed. Thermal balance equation is written for each thermal node leading to a linear system of equations, which can be easily solved step-by-step. The interested reader can find further details on the DigiThon model in the reference [11].

\subsection{Characterization of the climatic chamber}

In this paragraph, the assessment of DigiThon model is described, starting from data obtained during a measurement campaign carried out between 27/10/2020 and 11/11/2020. During these experiments, different radiant panels were switched on in heating mode; the walls were tested separately and the duration of each test was at least 24 hours; in order to evaluate the thermal behaviour of the radiant panels also in the switch-off phase, it was decided to keep at least 24 hours between two successive tests. For the whole duration of the measurement campaign, the acquisition system collected data, regardless of whether the system is switched on or not; monitored parameters were the surface temperatures of the walls, from which the surface average temperature was calculated and the air temperature at different height in the room; moreover, the mean radiant temperature and the relative humidity were detected. All these tests were performed with lowered blinds on windows, in order to avoid direct component of solar radiation entering the room. During tests, outdoor windows and the door adjacent to the external corridor were closed. 
All the radiant walls were tested, except for the floor where the sensors were not applied at that time in order to facilitate the presence of people inside the room. In each test, the supply temperature was set, and the variation of the measured parameters was monitored. Concerning this work, it was decided to fix at $42^{\circ} \mathrm{C}$ the supply temperature for tests of the north, east and south walls; for the west wall, the supply was set at $40^{\circ} \mathrm{C}$ and for the ceiling the temperature of $35^{\circ} \mathrm{C}$ was chosen.

In these tests, the mechanical ventilation system was not used, and its characterization will be the focus of future works.

The collected data for the outdoor air temperature and the solar radiation were provided by ARPAV [14], for the city of Padova for the investigated period. These values were used as inputs in the DigiThon model. Besides, the following boundary conditions were used for all the simulations:

- according to the laboratory configuration, the air temperatures in the adjacent rooms were measured during the tests and set as a boundary condition for the walls that are adjacent to the heated zones (north, south, west and floor walls);

- a convective boundary condition with outside air temperature was used for the external surfaces (ceiling and east wall);

- a shading coefficient of 0.2 was applied to the windows, to simulate the effect of the blinds, which avoid the direct solar radiation entering the room.

In all the simulations the same initial conditions of the tests were set. In Table 1, an overview of the tests that were carried out is provided.

Table 1. Tests duration and description.

\begin{tabular}{|c|c|c|c|c|}
\hline Test & Start time & Finish time & Duration & Description \\
\hline $\mathrm{A}$ & $\begin{array}{c}17 / 10 / 2020 \\
12: 30\end{array}$ & $\begin{array}{c}18 / 10 / 2020 \\
12: 30\end{array}$ & $24 \mathrm{~h}$ & $\begin{array}{c}\text { Switching on of the north wall } \\
\text { radiant panel. Other panels off. }\end{array}$ \\
\hline $\mathrm{B}$ & $\begin{array}{c}29 / 10 / 2020 \\
17: 30\end{array}$ & $\begin{array}{c}30 / 10 / 2020 \\
19: 30\end{array}$ & $26 \mathrm{~h}$ & $\begin{array}{c}\text { Switching on of the east wall radiant } \\
\text { panel. Other panels off. }\end{array}$ \\
\hline $\mathrm{C}$ & $\begin{array}{c}02 / 11 / 2020 \\
16: 15\end{array}$ & $\begin{array}{c}03 / 11 / 2020 \\
18: 15\end{array}$ & $26 \mathrm{~h}$ & $\begin{array}{c}\text { Switching on of the south wall } \\
\text { radiant panel. Other panels off. }\end{array}$ \\
\hline $\mathrm{D}$ & $\begin{array}{c}05 / 11 / 2020 \\
13: 00\end{array}$ & $\begin{array}{c}06 / 11 / 2020 \\
17: 00\end{array}$ & $28 \mathrm{~h}$ & $\begin{array}{c}\text { Switching on of the west wall radiant } \\
\text { panel. Other panels off. }\end{array}$ \\
\hline $\mathrm{E}$ & $\begin{array}{c}09 / 11 / 2020 \\
11: 00\end{array}$ & $\begin{array}{c}10 / 11 / 2020 \\
12: 30\end{array}$ & $25.5 \mathrm{~h}$ & $\begin{array}{c}\text { Switching on of the ceiling radiant } \\
\text { panel. Other panels off. }\end{array}$ \\
\hline
\end{tabular}

\subsection{Test on radiant asymmetry}

Some tests to evaluate the temperature limits for radiant ceiling to avoid discomfort conditions caused by radiant asymmetry were carried out. These experiments were performed with the heated ceiling, considering two different supply temperatures for warm water $\left(38^{\circ} \mathrm{C}\right.$ and $\left.42^{\circ} \mathrm{C}\right)$. The floor and the external wall were cooled, to simulate a noninsulated wall and a floor adjacent to a non-heated ambient. The cooled surfaces were supplied with $18^{\circ} \mathrm{C}$ water; the ventilation system in the laboratory was switched off.

The activity scheduling of the tests is shown in Table 2 .

The evaluation of the radiant asymmetry was made considering the temperatures detected from different sensors placed on the wall surfaces. For each wall, the average temperature was calculated at regime, i.e. when the temperature variation between two successive 10 minutes time steps was lower than $0.25^{\circ} \mathrm{C}$ ).

The radiant asymmetry was evaluated assuming the presence of a seated person $(0.6 \mathrm{~m}$ height) at the centre of the room. 
Table 2. Tests scheduling.

\begin{tabular}{|c|c|l|}
\hline Date & Hour & \multicolumn{1}{c|}{ Activity } \\
\hline $21 / 12 / 2020$ & $09: 30$ & Starting of acquisition system. \\
\hline & $11: 00$ & $\begin{array}{l}\text { Switching on radiant systems. Supply temperature equal to } 38^{\circ} \mathrm{C} \text { for the } \\
\text { ceiling, } 18^{\circ} \mathrm{C} \text { for east wall and the floor. }\end{array}$ \\
\hline & $18: 00$ & Switching off radiant systems. \\
\hline $22 / 12 / 2020$ & $09: 30$ & $\begin{array}{l}\text { Switching on radiant systems. Supply temperature equal to } 42^{\circ} \mathrm{C} \text { for the } \\
\text { ceiling, } 18^{\circ} \mathrm{C} \text { for east wall and the floor. }\end{array}$ \\
\hline & $17: 00$ & Switching off radiant systems \\
\hline
\end{tabular}

The Equation (1) was used for the calculation of the mean radiant temperature, while the plane radiant temperature difference $\left(\Delta T_{p, r}\right)$ was computed as the average radiant temperature difference between the two half-spaces in the room divided by a horizontal plane using the corresponding view factors.

$$
T_{m r}=\Sigma_{k} F_{v, p-k} \cdot T_{s, k}
$$

Where $T_{m r}$ is the mean radiant temperature, $F_{v, p-k}$ are the view factors between the person at the centre of the room and the $k$-th surface and $T_{s, k}$ is the average wall surface.

\section{Results}

\subsection{Model assessment results}

In this section, the comparison between the results obtained with the DigiThon simulations and the measured data is presented. The purpose of this study is to check the good correspondence between the numerical simulations and the experimental data.

In particular, Figures 6-10 report the temperature profiles obtained through both the tests and the simulations, considering the boundary conditions described in Section 3.1. On the left graph of each figure the following results are shown:

- The four different wall surface temperatures detected by the sensors;

- The average surface temperature, calculated as arithmetic mean of the previous ones;

- The average temperature obtained from the simulations (e.g. the blue dashed line);

- The average air temperature, calculated as the arithmetic mean of the measured values at different heights in the centre of the room. This last value has been reported to highlight its increasing trend as the surface temperature rises.

On the right graph, a focus on the air temperature is reported to underline the stratification effect which can be noticed by observing the temperature profiles at different heights: the higher the sensor position, the higher the air temperature; besides, these profiles are compared with the air temperature obtained from simulations (e.g. the purple-dotted line).

All the wall tested have shown a similar behaviour after the switching on of the radiant system: in a short time, the sensors detect a rapid increase in the surface temperatures, which after a few minutes stabilises around a stable value.

In some cases, the wall temperature is not constant, which means that the temperature profiles show some fluctuations. This is due to the different operating conditions of the heating system. Indeed, in Cases A, B and D, the storage tank, which provides the warm water to the radiant system, was heated using only one of the three available electric 
resistances. However, the high heating load demanded by the test room and the high set supply temperatures led to an intermittent operation of the heating system, with frequent on-offs of the resistance, causing the oscillation of both the supply and the wall surface temperature. On the other hand, the constant behaviour of the wall temperatures in Cases C and $\mathrm{E}$ can be related to the use of all the electric resistances inside the thermal storage tank (Case C) and to a lower set supply temperature (Case E).

In all the analysed cases, it can be noticed that the temperature profiles detected by the different sensors positioned on each wall are very close among them, this is an indicator of a good temperature uniformity on the surface.

The highest difference between the mean value and each single measured value was found for Case $\mathrm{E}\left(1.43^{\circ} \mathrm{C}\right)$ and Case $\mathrm{B}\left(0.92^{\circ} \mathrm{C}\right)$.
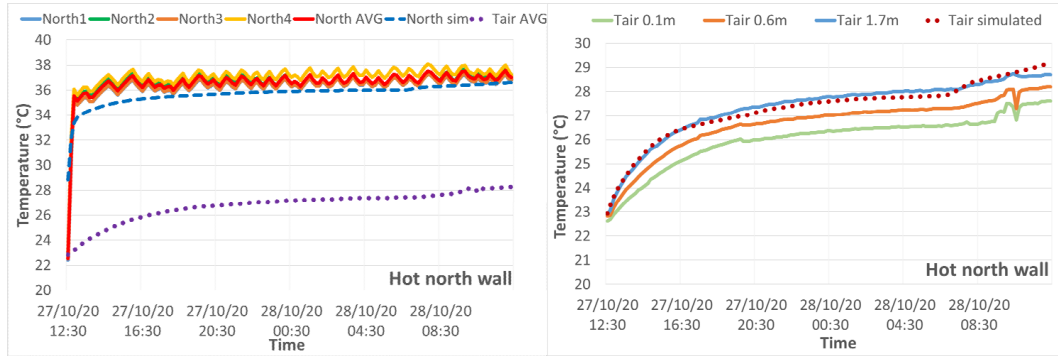

Fig. 6. Surface wall temperature (left) and air temperature (right) profiles for both measurements and simulation with north wall radiant panels switched on in heating mode (Case A).
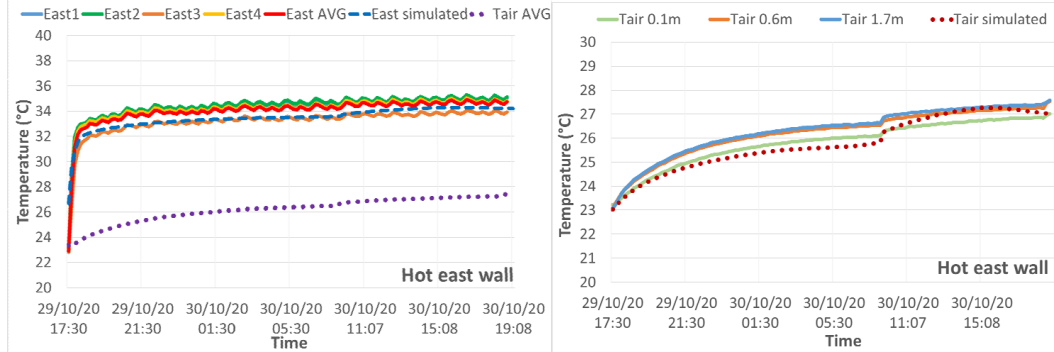

Fig. 7. Surface wall temperature (left) and air temperature (right) profiles for both measurements and simulation with east wall radiant panels switched on in heating mode (Case B).
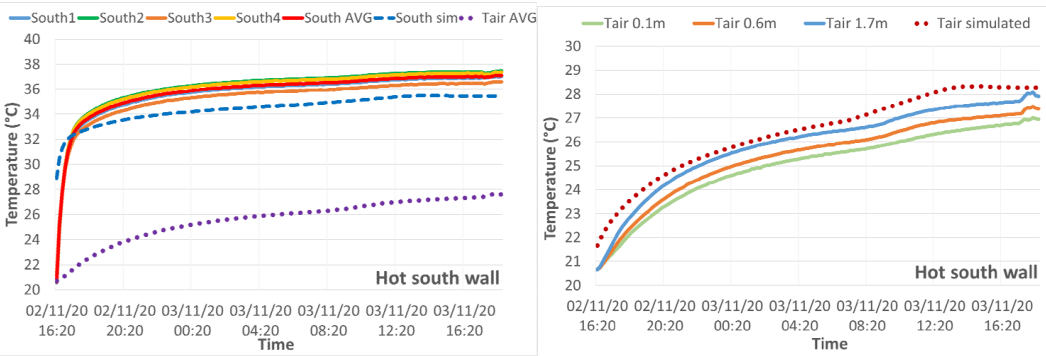

Fig. 8. Surface wall temperature (left) and air temperature (right) profiles for both measurements and simulation with south wall radiant panels switched on in heating mode (Case C). 

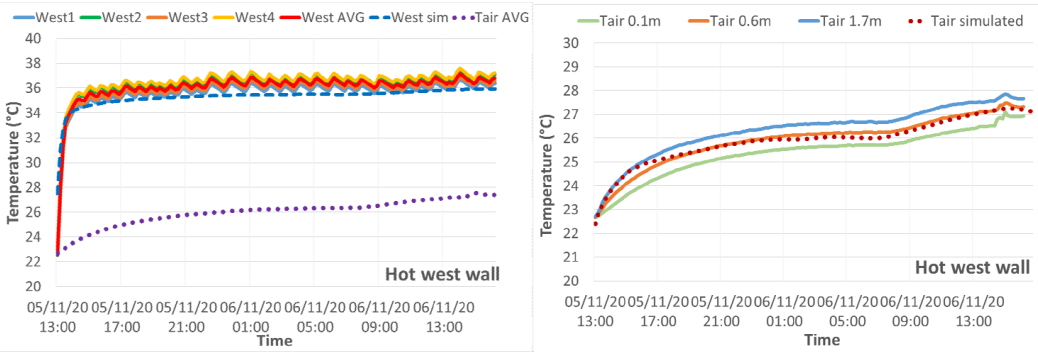

Fig. 9. Surface wall temperature (left) and air temperature (right) profiles for both measurements and simulation with west wall radiant panels switched on in heating mode (Case D).
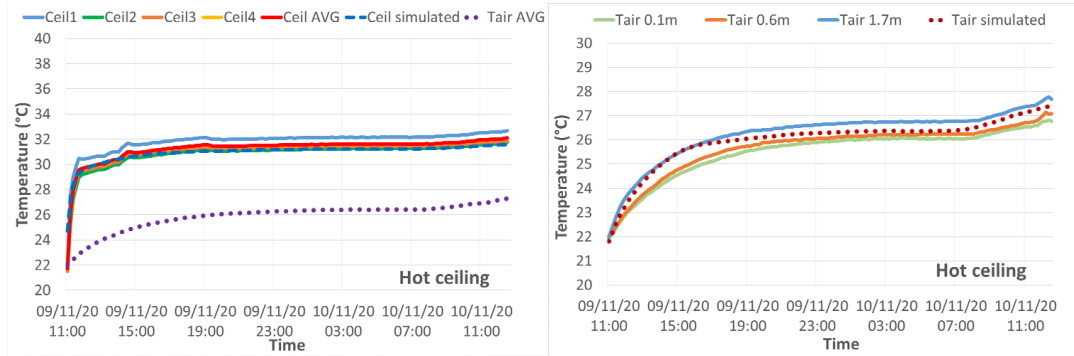

Fig. 10. Surface wall temperature (left) and air temperature (right) profiles for both measurements and simulation with ceiling radiant panels switched on in heating mode (Case E).

The good match between the average measured surface temperature and the one obtained from simulations points out that the model is able to represent the characteristics of the radiant panels in all the tested surfaces (Table 3).

Concerning the air temperature, the graphs show the different temperature profiles measured at each column height level. A slight stratification was found in all cases, but the vertical temperature gradients were different in each case; in particular, during the tests on the radiant panel placed in the east wall (Case B) the vertical gradient seems to be more attenuated. The maximum temperature difference measured between the $1.7 \mathrm{~m}$ and $0.1 \mathrm{~m}$ high sensors is always found at the end of the test. A smaller difference is found when the external walls are cooled $\left(0.63^{\circ} \mathrm{C}\right.$ in Case $\mathrm{B}$ and $0.96^{\circ} \mathrm{C}$ in Case $\left.\mathrm{E}\right)$; the tests on the north and west walls show similar temperature difference values $\left(1.12^{\circ} \mathrm{C}\right.$ for Case $\mathrm{A}$ and $1.13^{\circ} \mathrm{C}$ for Case D); finally, the highest stratification is found in Case $\mathrm{C}$, with a maximum difference of $1.86^{\circ} \mathrm{C}$.

The air temperature profiles show a similar pattern for the different cases: the test starts with a homogeneous room temperature and, after the system is switched on, the temperature slowly increases and vertical gradients begin to establish. Since all tests started in the late morning or afternoon, it can be seen that the temperature tends to stabilise during the night, while increases in the morning due to the rise of external temperature and solar radiation.

Compared to the case of the surface temperature, the correspondence between the simulated and measured air temperature profiles is less evident; however, in the laboratory there is no homogeneous distribution of the sensors in the air volume, but there is only the detection at a column in the centre of the room. In contrast, the DigiThon model considers one only air temperature node; therefore, a larger deviation is acceptable. 
Finally, from the analysis carried out, it is possible to conclude that, concerning both the correlation between supply and surface temperatures and the air temperature profiles, the DigiThon model gave an accurate assessment of the laboratory behaviour in all the simulated cases. In Table 3, the root mean square error (RMSE) between measured and simulated data for both air and surface temperature is showed. In Table 4, for each case, the supply water temperature used for both tests and simulations is compared with the average surface temperature of the corresponding wall.

Table 3. RMSE between measurements and simulations for all the cases.

\begin{tabular}{|c|c|c|c|c|c|}
\hline & North wall & East wall & South wall & West wall & Ceiling \\
\hline Surface Temperature & 1.40 & 1.25 & 1.67 & 0.71 & 0.41 \\
\hline Air Temperature & 0.41 & 0.50 & 0.75 & 0.10 & 0.36 \\
\hline
\end{tabular}

Table 4. Supply water temperature and surface wall temperature for each case.

\begin{tabular}{|c|c|c|c|c|}
\hline Case & $\begin{array}{c}\text { Supply water } \\
\text { temperature }\end{array}$ & $\begin{array}{c}\text { Initial surface wall } \\
\text { temperature }\end{array}$ & $\begin{array}{c}\text { Average measured } \\
\text { wall temperature }\end{array}$ & $\begin{array}{c}\text { Average simulated } \\
\text { wall temperature }\end{array}$ \\
\hline $\mathrm{A}$ & $42^{\circ} \mathrm{C}$ & $22.5^{\circ} \mathrm{C}$ & $36.7^{\circ} \mathrm{C}$ & $35.7^{\circ} \mathrm{C}$ \\
\hline$B$ & $42^{\circ} \mathrm{C}$ & $22.9^{\circ} \mathrm{C}$ & $34.1^{\circ} \mathrm{C}$ & $33.5^{\circ} \mathrm{C}$ \\
\hline $\mathrm{C}$ & $42^{\circ} \mathrm{C}$ & $20.6^{\circ} \mathrm{C}$ & $36.0^{\circ} \mathrm{C}$ & $34.4^{\circ} \mathrm{C}$ \\
\hline$D$ & $40^{\circ} \mathrm{C}$ & $22.6^{\circ} \mathrm{C}$ & $36.2^{\circ} \mathrm{C}$ & $35.5^{\circ} \mathrm{C}$ \\
\hline$E$ & $35^{\circ} \mathrm{C}$ & $21.7^{\circ} \mathrm{C}$ & $31.3^{\circ} \mathrm{C}$ & $31.0^{\circ} \mathrm{C}$ \\
\hline
\end{tabular}

\subsection{Radiant asymmetry results}

Results of the tests are shown in Figure 11, where the variation of $\Delta T_{p, r}$ over time is reported. The average values of $\Delta T_{p, r}$ calculated in steady conditions are reported in Table 5 . In case of a supply water temperature setpoint of $38^{\circ} \mathrm{C}$, the measured $\Delta T_{p, r}$ is acceptable, although very close to the $5^{\circ} \mathrm{C}$ comfort limit established by Fanger (1980). On the other hand, changing the supply temperature setpoint to $42^{\circ} \mathrm{C}$ results in uncomfortable conditions for radiant asymmetry.

Table 5. Average values of the $\Delta T_{p, r}$ calculated from tests.

\begin{tabular}{|c|c|}
\hline Supply water temperature & $\Delta \boldsymbol{T}_{\boldsymbol{p}, \boldsymbol{r}}$ \\
\hline $38^{\circ} \mathrm{C}$ & $4.74^{\circ} \mathrm{C}$ \\
\hline $42^{\circ} \mathrm{C}$ & $5.63^{\circ} \mathrm{C}$ \\
\hline
\end{tabular}

In Figure 12, the air temperature profiles are reported. The simultaneous presence of a hot ceiling and a cool floor, increase the vertical air gradients, which is higher than in the tests in Subsection 4.1: with a supply temperature of $38^{\circ} \mathrm{C}$, the maximum air temperature difference between the $1.7 \mathrm{~m}$ and $0.1 \mathrm{~m}$ high sensors is $2.25^{\circ} \mathrm{C}$, while in the second case the same parameter was found to be $2.71^{\circ} \mathrm{C}$. 


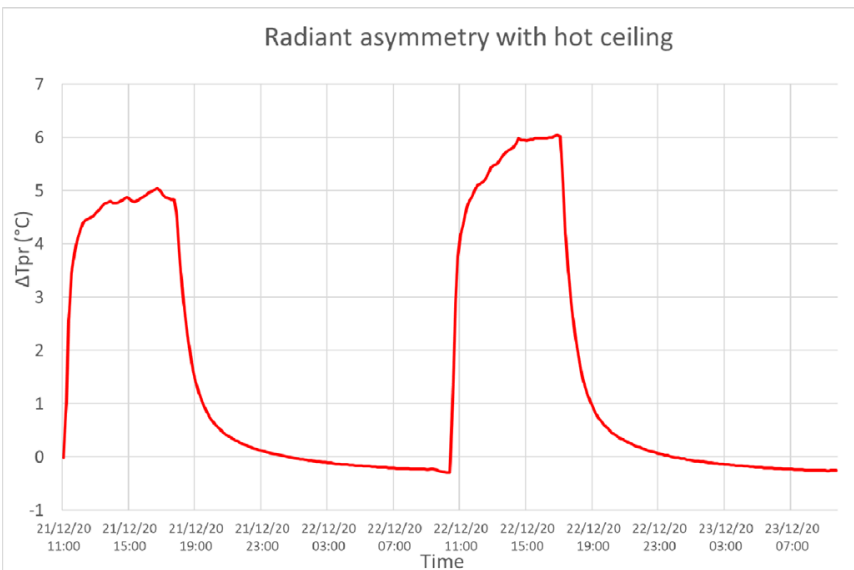

Fig. 11. $\Delta \mathrm{T}_{\mathrm{p}, \mathrm{r}}$ profile obtained from tests.

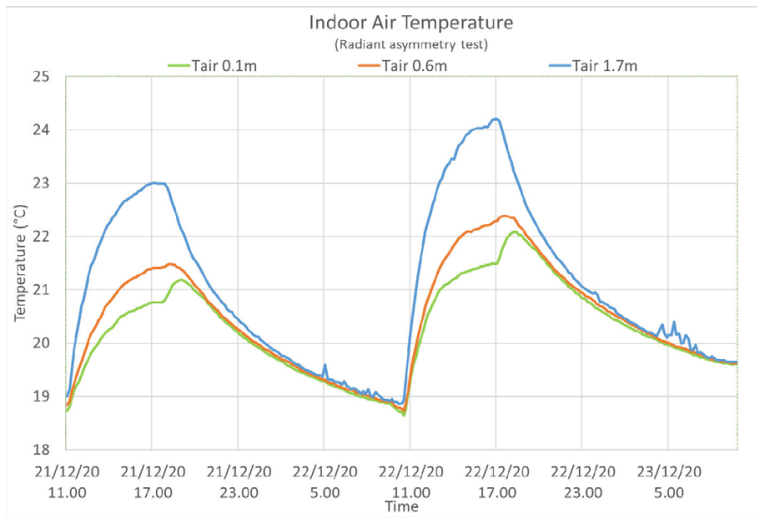

Fig. 12. Air temperature at different heights measured during tests on radiant asymmetry.

\section{Conclusions}

In this work, the CORE-CARE climatic chamber is presented. Some tests were carried out to describe the dynamic behaviour of the room. The results of these tests were compared with the output of numerical simulations with the software DigiThon.

The different analyses consisted of switching on each radiant wall separately in heating mode, with different supply water temperatures, checking the air temperatures at different heights and the wall surface temperatures. In addition, a test with heated ceiling and cooled floor and outer wall was performed to investigate the comfort limits for radiant asymmetry.

Some results can be deduced from this work:

- The DigiThon software reproduces a realistic model of the climate chamber, and there is a good correspondence between the measured and simulated temperature profiles;

- The temperatures measured by the different probes showed a slight difference between them, with a uniform temperature throughout the wall; 
- In all the tests stratification has occurred, to varying degrees depending on which wall was heated. However, the temperature difference never exceeded the $3^{\circ} \mathrm{C}$;

- Test on radiant asymmetry showed that in the chamber, heated ceiling with $42^{\circ} \mathrm{C}$ water supply temperature and cooled floor and external surface with $18^{\circ} \mathrm{C}$ water supply temperature leads to a $\Delta T_{p, r}$ of $5.63^{\circ} \mathrm{C}$, which exceeds the $5^{\circ} \mathrm{C}$ temperature limit for comfort conditions. Conversely, in case of $38^{\circ} \mathrm{C}$ supply water, the $\Delta T_{p, r}$ is $4.74^{\circ} \mathrm{C}$, within comfort limits.

\section{References}

[1] P.O. Fanger, Calculation of thermal comfort: introduction of a basic comfort equation, ASHRAE Trans., 73, III.4.1-III.4.20 (1967)

[2] P.O. Fanger, L. Banhidi, B.W. Olesen, G. Langkilde, Comfort limits for heated ceilings, ASHRAE Trans., 86, 141-156 (1980)

[3] P.O. Fanger, B.M. Ipsen, G. Langkilde, B.W. Olesen, N.K. Christensen, S. Tanabe, Comfort limits for asymmetric thermal radiation, Energy Build., 8, 225-236 (1985)

[4] X. Zhou, Y. Liu, M. Luo, L. Zhang, Q. Zhang, X. Zhang, Thermal comfort under radiant asymmetries of floor cooling system in $2 \mathrm{~h}$ and $8 \mathrm{~h}$ exposure durations, Energy Build., 188-189, 98-110 (2019)

[5] S. Olesen, J.J. Bassing, P.O. Fanger, Physiological comfort conditions at sixteen combinations of activity, clothing, air velocity and ambient temperature, ASHRAE Trans., 78, 199-206 (1972)

[6] L. Schellen, W.D. van Marken Lichtenbelt, M.G.L.C. Loomans, J. Toftum, M.H. de Wit, Differences between young adults and elderly in thermal comfort, productivity, and thermal physiology in response to a moderate temperature drift and a steady-state condition, Indoor Air., 20, 273-283 (2010)

[7] C. Cen, Y. Jia, K. Liu, R. Geng, Experimental comparison of thermal comfort during cooling with a fan coil system and radiant floor system at varying space heights, Build. Environ., 141, 71-79 (2018)

[8] H. Sun, Z. Yang, B. Lin, W. Shi, Y. Zhu, H. Zhao, Comparison of thermal comfort between convective heating and radiant heating terminals in a winter thermal environment: A field and experimental study, Energy Build., 224, 110239 (2020)

[9] T. Catalina, J. Virgone, F. Kuznik, Evaluation of thermal comfort using combined CFD and experimentation study in a test room equipped with a cooling ceiling, Build. Environ., 44, 1740-1750 (2009)

[10] Q. Dong, S. Li, C. Han, Numerical and experimental study of the effect of solar radiation on thermal comfort in a radiant heating system, J. Build. Eng., 32, 101497 
(2020)

[11] M. De Carli, M. Scarpa, R. Tomasi, A. Zarrella, DIGITHON: A numerical model for the thermal balance of rooms equipped with radiant systems, Build. Environ., 57, 126-144 (2012)

[12] G.P. Mitalas, Cooling load calculations by thermal response factors, ASHRAE Trans., 73, III.1.1-III.1.7 (1967)

[13] T. Kusuda, Thermal response factors for multi-layer structures of various heat conduction sys-tems, ASHRAE Trans., 75, 241-271 (1969)

[14] ARPAV, Agenzia Regionale per la Prevenzione e per la Protezione Ambientale del Veneto (2020). http://www.arpa.veneto.it 